\title{
Digital text production as narrative: an analysis of text production in a multilingual classroom at primary school
}

\author{
Anna Lyngfelt \\ University of Gothenburg, Faculty of Education, Sweden; anna.lyngfelt@gu.se
}

\begin{abstract}
In the study presented digital text production in a multilingual classroom is discussed. This involves students aged 7-8, manifesting their literacy by making use of both their writing and reading competence. To be able to discuss the text production, Bakhtin's theories about heteroglossia are crucial, allowing for both social and historical contexts of utterances (Bakhtin 1994). These theories are here intertwined with Bruner's notion of human beings as constituted by 'narratives' (Bruner 2002). By the use of linguistic ethnography (Creese 2008) and text analysis based on sociosemiotics (Kress, van Leeuwen 2006), the following questions are discussed: How do multilingual students make use of digital tools for meaning making in their digital text productions, and in what sense could they by creating these texts be said to contribute to their own literacy development? Text productions from four students are analysed to illustrate how multivocal spaces are created, and how these 'spaces' can explain the students' literacy development.
\end{abstract}

Keywords: meaning making, literacy processes, multilingualism, narratives, sociosemiotics

\section{Introduction}

The aim of this paper is to discuss digital text production in a multilingual classrooms a manifestation of literacy, constituted by both reading and writing competence. The creation of digital texts is considered to be the result of literacy approaches, where bottom up-readers as well as top downreaders manifest their competence by the creation of digital texts, using all possibilities available to them. Digital tools are here considered not only as a means for communication, but also as a way of developing literacy. By letting multilingual students get the chance to express themselves multimodally, while responding to a written assignment in Swedish, the students demonstrate their work with combining linguistic capacity with non-verbal communication; through their text productions it becomes clear how the students struggle to manifest and develop their literacy.

Below, the students' text productions are considered to be the result of the creation of multivocal spaces, which in turn is regarded to bet he result of discursive practices taking into account social and historical contexts that individually and collectively matter to the students involved. As Tierney (2018) writes, we have the capabilities to support different languages and various modes of thinking and expressions in our educational systems - a statement which here opens the way for an understanding of a variety of meaning making in an educational setting, locally. To approach multilingual students' text productions, and consider them to be the result of multivocal spaces created by the students, is therefore an attempt to grasp and develop a view of the students' text productions as 'global meaning making' (Tierney 2018). By focusing on what is being manifested in the text productions, the students' roles as agents in a process are fore groundedand explained as self-determination.

By the use of linguistic ethnography, possible answers to two questions will be discussed: How do multilingual students, aged 7-8, make use of digital tools for meaning making in their digital text productions, and in what sense could they by creating these texts be said to contribute to their own literacy development? For this a theoretical framework is needed, stressing the importance of the social and historical contexts that individually and collectively matter to the students.

\section{Literacy and translanguaging}

As Heath once stated (1983), a 'literacy event' could be described as any occasion in which a piece of writing is integral to the nature of the participants' interactions and their interpretative processes. According to Street (1984) and Barton (1994), these events could be explained as 'literacy practices', since they include both social practices and conceptions of reading and writing. Yetit is rare to find studies where both reading and writing are approached as intertwined (Lyngfelt 2018). Also, when multilingual classrooms receive attention, the approach is often either linguistic or oriented towards 
social and cultural circumstances. Studies seldom make use of the complexity that the term literacy tries to capture: 'literacy' as processes and products at the same time, dependant on conceptions of what reading and writing are andc ould be to students, as a result of the possibilities and limitations that specific situations offer.

Theoretically and methodologically, translanguaging (Garcia \& Wei 2014) and linguistic ethnography (Creese 2008) make it possible to consider reading and writing as intertwined social activities; the conception of literacy as translanguaging (Garcia \& Wei 2014) captures a complexity that is here understood as an approach to the use of languages, where multilingual students practice language systems including combinations of different modes like text, still images, sound etc. (Kress \& van Leeuwen 2006, Jewitt 2008, Bearne 2009). Also, 'translanguaging' makes it possible to take discursive practices into account; it facilitates the understanding of the social context in which 'languaging' (Swain 1985) takes place. As Garcia writes, translanguaging makes it possible to grasp multiple discursive practices in which bilinguals engage, in order to make sense of their bilingual worlds (Garcia 2009). This, in turn, creates opportunities to consider the multilingual students' conditions and social circumstances during their literacy practice, which Wei (2011) refers to as their 'translanguaging space'.

\section{Multivocal spaces and literacy}

In this context, translanguaging space is understood as a space where 'translation' takes place between traditions of reading and writing at school, and digital experiences acquired outside school, and these combine into new identities for the students. As Dewilde writes (2016), the boundaries of imagined translanguaging spaces shift, since individuals create the rules of interaction and interpretation within these spaces, in line with the individuals' perception of boundaries. However, what adds complexity to these (individual) spaces is the fact that they are linked to spaces created by others, since individuals' experiences, attitudes and values are acquired in interaction with others and as a result of certain social conditions. As Wei points out, translanguaging space is a 'lived space', created by social practices in everyday life (Wei 2011). Here, this means that traces from the students' broader linguistic repertoires co-exist and contribute to the creation of a diversity of translanguaging spaces, in the school setting where the students find themselves.

However, the concept of 'heteroglossia' is needed to deepen the understanding of translanguaging and translanguaging spaces. As Bailey (2007) points out, inspired by Bakhtin (1994), there is a need for focus on 'voice' rather than language when discussing utterances; as Bakhtin writes there are in every utterance traces not only of the social and political forces that have shaped it but also historical forces. This means, for Bakhtin, that heteroglossia allows for theorizing of both social and historical contexts of utterances, and by doing so letting the here-and-now draw meaning from the past. Hence, linguistics needs to be intertwined with sociohistorical views of human interaction, if (like here) students' text productions should be understood as the result of a literacy practice, where students put efforts into making use of their pre-understanding as well as up-to-date knowledge.

Thus, 'translanguaging space' may be considered to be inadequate as a conception. The term multivocal space is therefore suggested, to capture not only voices making themselves heard in the same space of an individual (here-and-now), but also echoes of social and historical contexts that contribute to the constituting of the individual's space; multivocal spaces do not limit discursive practices to 'lived spaces' created by social practices in everyday life, but take into account social and historical contexts that individually and collectively matter to the students involved. Also, this is an attempt to contextualize global meaning making as "modes of operation of people who cross the line" (Tierney 2018: 12), who are skilled at adaptation and engage in digital innovations or forms of translanguaging, especially along borders where cultures cross or brush up against one another (Kim 2016).

Since texts are looked upon as a part of daily practice, the students' experiences of literacy, acquired inside and outside school, are likely to play a role in their digital text production; to be able to create multivocal spaces they both have to make use of competence they have, and adapt to what is expected from them in the school context. Thus, it is likely that there are traces of different strategies for approaching text in the students' text productions, i.e. both students demonstrating bottom-up 
processing, by being careful with individual meanings or grammatical characteristics of the most basic units of the text, and out of that creating whole texts, as well as students that use top-down strategies to produce their texts (and of course strategies in between, constituted by shifts in perspectives). By top-down processing, the students make the most of what they bring to the situation, and out of that develop a structure with details necessary for the receiver of the text production. To conclude, if literacy includes both reading and writing, conceptions of reading processes may be relevant also for writing processes. However, to be able to analyse these complex processes, linguistic ethnography is needed, as well as analytical tools derived from sociosemiotics (Kress \& van Leeuwen 2006).

\section{Linguistic ethnography and tools from sociosemiotics}

As Creese (2008) writes, it is the consideration of what is to be gained by conjoining the two terms linguistics and ethnography that defines linguistic ethnography. Within this field, ethnography can benefit from the analytical frameworks provided by linguistics, while linguistics can benefit from processes of reflexive sensitivity required in ethnography. While linguistics provides an authoritative analysis of language use not typically available from participant observation and the taking of field notes, ethnography provides linguistics with a close 'reading' of social context. Accordingly, linguistic ethnography helps to combine close detail of local action with interaction embedded in a wider social world. Consequently, the students' texts are here viewed as processual and constructed in social discourse and action; ethnography contributes to the unravelling of details of how language varieties and discourses work for the students involved (Blommaert 2010).

It is from this perspective that the idea of texts as praxis is relevant. However, here texts are also regarded as narratives. As Bruner stresses, we are narratives and become what we tell about (Bruner 2002). By this he means that we become autobiographical narratives by which we tell about our lives, since the ways of telling and the ways of conceptualizing become so habitual that they finally become forms for structuring experience itself, guiding the 'life narrative' not only up to the present but also into the future. Accordingly, life is how it is interpreted and reinterpreted, told and retold.

In this context, narratives are considered to contribute to shifts in the students' perspectives, by the use of personal experiences acquired both inside and outside school, making the students 'life stories' unstable; narratives are thought to be facilitated by the opportunity to use a variety of digital tools, opening up for 'possible life stories'. Considering the rapidly changing media landscape, this approach seems relevant; the 'voices' in use by the students are made possible by the resources of new media. As Vasquez and Felderman (2013) point out, most young children are immersed in digital practices from an early age, and even if they do not have access to digital technologies at home, they are often able to develop skills in working with digital texts and tools (Bearne 2009).

To sum up, since everything anybody ever says always exists in response to things that have been said before, and in anticipation of things that will be said in response (cf. Bakhtin 1981), the students' text productions are conceived as multivocal spaces consisting of narratives; the students' text productions are regarded as being constituted by 'voices', including interpersonal experiences acquired inside and outside school, revealing ideas about what the students would like to become as well as thoughts of how they perceive themselves while creating their texts. In the context, it is of course of special interest to see what the students reveal that they would like to become as readers and writers, and how they reveal what matters to them in the role of 'writers' of digital text production.

For this purpose - to catch how multivocal spaces are created by the narratives constituting the texts - tools derived from sociosemiotics are used here. Following the work of Kress and van Leeuwen (2006), it is important to study how signs are put to use and received, since small signs - like the combination of images and signs - may have significant consequences for the students' meaning making. However, in the context, Cope and Kalantzis' (2010) notion of what digital tools have a capacity to change is also important; Cope and Kalantzis suggest that the resources that new media offer fundamentally change the conditions for text production and that this, in turn, could be used as an asset from an educational point of view. Even if Cope and Kalantzis' main focus is not discussing literacy or language development, and even less multivocal spaces, their ideas about the changing balance of agency that new media offer, and the need for conceptualization when using new media, are relevant (Cope \& Kalantzis 2010: 96). In 
particular, Cope and Kalantzis' notion of the changing balance of agency is interesting, since according to them it makes the students co-designers rather than users of new media. Their notion of conceptualization, as a result of metacognition while making use of new media, is crucial as well, since it opens the way for understanding how multivocal spaces are constituted by the students (cf. Cope \& Kalantzis 2010).

\section{Students' creation of multivocal spaces: design of the study and results}

The empirical data draws upon empirical data collected within the research project Digital Arenas in Literacy Practices in Early Primary School, DILS $(2012-2016){ }^{23}$ The main objective here was the search for critical perspectives on classroom studies that focus on meaning making by the use of digital tools; the project aimed at increasing the understanding of students' and teachers' use of digital tools in classroom contexts. By studying digital interaction among the students, instructions from the teachers and the outcomes of various tasks where use of digital tools was needed, the use of multiliteracies was observed and related to sociocultural contexts (Sofkova Hashemi \& Cederlund 2017).

The project involved three classes in early primary school in Sweden, with pupils aged 7-9 and their teachers. These classes represented various socioeconomic backgrounds and were found in three schools situated in different places, one in a small town and two in different parts of a city. The focus here is limited to the work in one of the schools, the school characterized by a school setting where the students did not necessarily choose the majority language (Swedish) for communication in the classroom; an Arabic-speaking teacher is involved, and several of the students learn Swedish through Somali.

Even though text analysis was not the main focus of the DILS project, this study makes use of text analysis and interviews with four focal students in one of the city schools in order to look at the students' use of the digital resources available to them, in the multilingual classroom.

\section{The design of the study}

By the study of a written assignment, where students were asked to individually produce information for an (imaginary) alien arriving on earth for the first time, the students' digital text productions are investigated. To be able to create text productions, the students had the opportunity to choose between the use of computers and iPads for their 'texts'. As already indicated, four focal students, representative of the group of students as a whole when it comes to the variety of literacy development, were chosen for the text analyses and short interviews. Here they are called Zaid, Edy, Bina and Ramona, and they were all using iPads for their presentations - even though they had the choice to use computers. After having finished their text productions, during two lessons, these students were offered the opportunity to comment on their work one by one.

\section{Results of the study}

The results of the study show that agency, in terms of autonomy (for the students) instead of control (from the teachers' perspective), is likely to change the way outcomes are achieved. This is obvious from the text production of one of the four focal students, Zaid.

\section{Zaid}

Zaid efficiently combines sound, still images and words to make it clear to the alien what it needs on earth. By the use of eight still images (seven photos), he lets pictures be foregrounded and supported by his own voice telling (almost) the same thing as is written in small letters in the background of the pictures.

Image 1 consists of a photo of the written assignment that the students got, while the second image shows a sink and a water tap. Added to this second image is Zaid's voice saying, 'I taught it to drink

\footnotetext{
${ }^{23}$ This project was funded by the Marcus and Amalia Wallenberg foundation, in Sweden.
} 
water with his mouth'. In the background, in small letters, is written, 'It needs water' (with almost correct spelling ${ }^{24}$.

The third image consists of a desk in the classroom and a chair with a rucksack hanging on it. Added to this is Zaid's voice saying 'I taught it lots of words. The same information, 'I taught...' is printed in the background in small letters (with incorrect spelling). In the next image, number four, the reader is faced with papers on a table showing the solar system and hand-drawn pictures of planets. Here Zaid's voice says, 'I taught it lots, lots, lots of things about space.' However, Image 5 is informative, with a photo of the students' winter clothes hanging in the corridor. No text is added but Zaid's voice says 'I taught it needs clothes not to freeze to death'.

Text is omitted also in the next image, number 6 . Here the reader sees a photo of the swing in the schoolyard and Zaid's voice says, 'I taught it how to swing, using a swing'. Finally, in Image 7, there is a photo of a desk with a computer. No recorded voice is added but in small letters you can read, 'I taught it canteen is called computer' (with the ending omitted in 'called'). An additional image is also added, but without any photo (just a pink background) and tiny letters saying 'The end'.

To sum up, Zaid uses multiple resources for meaning making: sound, still images and words. He uses still images as a basis and his own recorded voice and typed letters to stress the messages conveyed by the pictures (photos) that constitute his text (picture two to seven). By letting the photos be foregrounded he manages to communicate efficiently; by showing the photos it would be easy for the receiver (the alien) to understand not only that water and clothes (etc.) are important but also what they look like and where to find them. By doing so, Zaid finds a way to communicate through the resources that (probably) suit him the best - photos and the use of his voice - instead of struggling with the spelling of words.

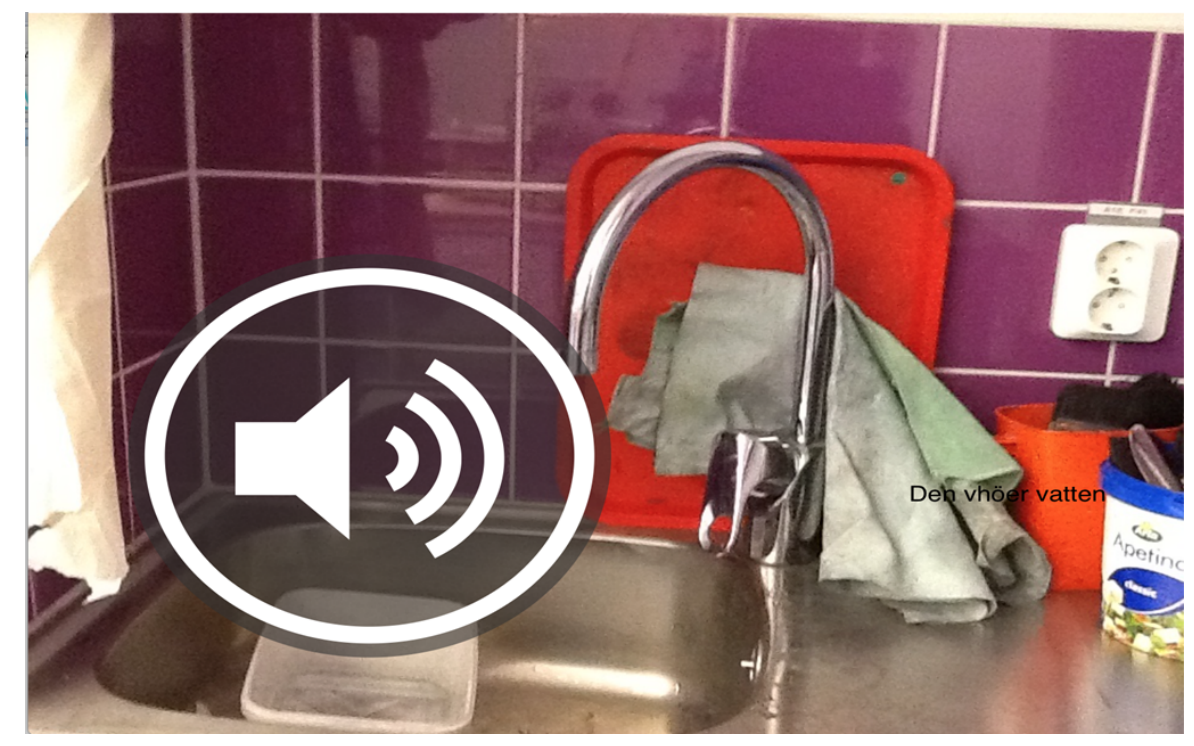

Zaid's Image 2.

In fact, written language is scarcely needed for the narrative in this text production. By his work, Zaid shows that learners can make use of a variety of available resources, in which they actively convey knowledge in its various modes and permutations. Also, this text production shows that the key shift in the use of new media is not the medium but the capacity to support learners to be knowledge producers rather than knowledge consumers. To Zaid, the changing balance of agency that new media opens the way for, makes a big difference; it draws attention to his knowledge and ability to communicate instead of focusing on his limited ability to use the majority language (Swedish). When

\footnotetext{
${ }^{24}$ I have made comments on the students' spelling in my text, to give the reader an idea of the kind of verbal language that characterizes the
} students' texts. 
commenting on his text in the interview, he refers to his text production by saying that 'if you start with a picture you could always add something to it if someone doesn't understand - sound, for instance'.

Zaid's text production could be looked upon as a result of top-down processing; he makes the most of what he brings to the situation, and develops a structure with details necessary for the receiver of the text production. His multivocal space could be regarded to be constituted by modes representing experiences that he himself knows are important for the alien (to be able to drink, etc.). Also, he uses his experience of what an iPad could be used for, when creating his text. In addition to this, Zaid could be said to contribute to his own literacy development, by starting his communication with still images, sound etc., and after that adding words that he knows in Swedish. By doing so he makes the most of his communicative abilities.

\section{Edy}

If photos carried the narrative in Zaid's text, written text dominates Edy's text production. The production consists of two still images: one with typed text in black on a green background and one with black text on a red background. To Image 1 , a recorded voice is added, where the student reads aloud what he has written, and to the text in Image 2, three pictures are added, showing photos of the alphabet on the wall of the classroom. If in Image 1, spoken and written text independently act as resources, the photos of the alphabet in Image 2 relate to the students' meticulous work with the written text rather than to the text content. Compared to Zaid's work, this text production is not very much developed from a multimodal perspective, probably because Edy finds his way into text production by starting to figure out what phonemes correspond to the graphemes he needs to be able to create words - one by one - to make sentences.

In fact, Edy's text production clearly shows the efforts of learning a new (verbal) language. Also, it should be pointed out that even if the spelling is far from perfect, the written text is informative and easy to understand. Among other things, like information on how you eat, Edy repeatedly tells the alien that it is important to go to an employment agency (Image 1). In the next image (Image 2), Edy is instead occupied with his own role when taking care of the alien ('I will warm you', 'we will go shopping', etc.).

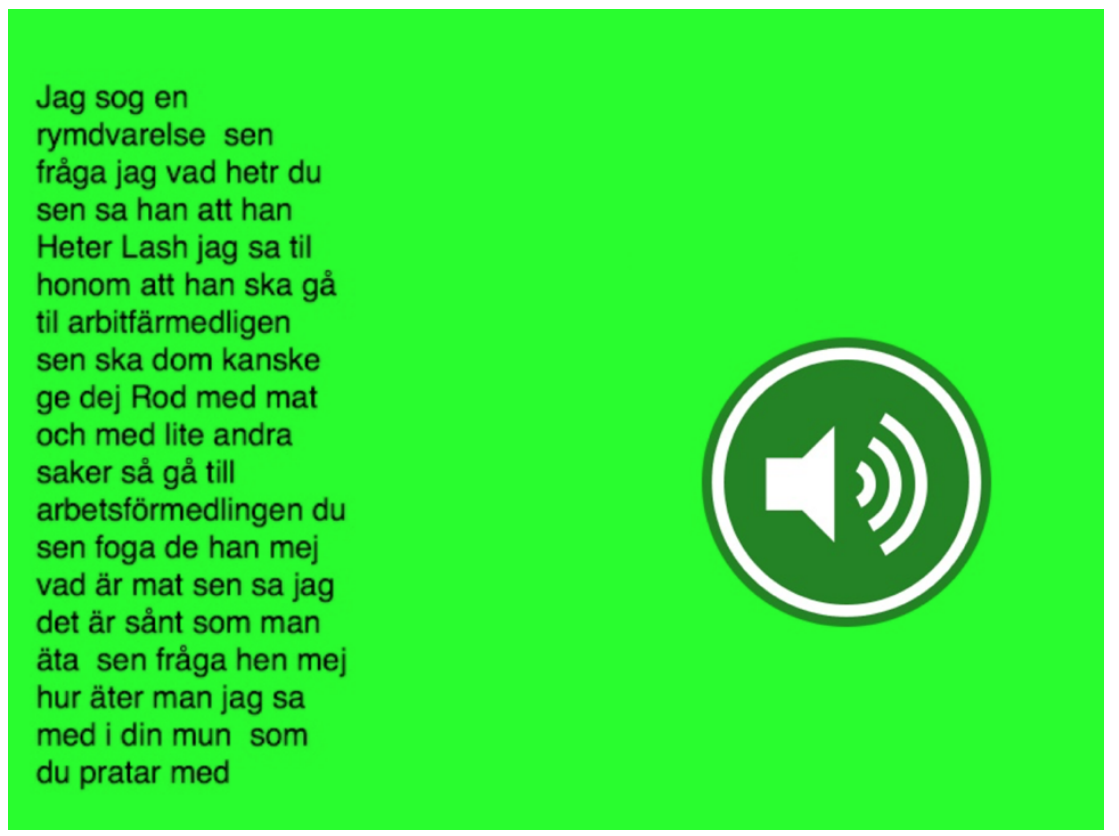

Edy's Image 1.

In spite of all the possibilities offered by digital tools, Edy's text production could be said to represent uniformity, since the use of modalities is limited. Nevertheless, this text production opens the way for considerations when it comes to diversity; it shows that the opportunity to use a variety of modalities 
can be rejected by one student while the others keep combining modalities in a variety of ways, in the same classroom. In this case, it is likely that the student chose the modalities that seemed adequate to him, for expressing himself and developing literacy.

It is worth noticing that the way Edy chose to create his text production fundamentally differs from how literacy is being taught in the classroom where he finds himself. ${ }^{25}$ Thus, the diversity of text production that digital texts reveal may give important information to teachers about how the students work when struggling to learn to read and write. In this case the student is obsessed by letters; when being interviewed, he keeps referring to his text by reading it aloud, pronouncing one letter after another.

It could be argued that the 'voices' that Edy's experiences from outside school represent - that it is important to visit the employment agency, etc. - dominate his narrative and by doing so constitute a multivocal space. However, his struggle with achieving literacy at school seems to be just as important to him, which means that his narrative also tells something about how eager Edy is to be able to read and write. Without being conscious of it himself, his working process could be categorized as a bottomup process; Edy is very careful with individual meanings or grammatical characteristics of the most basic units of his text, and out of that creates his whole text. He could also be said to take responsibility for his own literacy development, by reading aloud and focusing on word forms rather than meaning. In addition to this, it could be argued that when it comes to multivocal space, Edy's 'space' is less open for communication than Zaid's. Even though Zaid's communication is mainly non-verbal, his multivocal space is not a closed universe in the sense that Edy's text is. One example of this is Edy's dialogue with himself while recording the reading of what he has written (which is a part of his text production). This could be compared with Zaid's less form-centred efforts (verbally), to convey (content) oriented messages as a 'writer', concentrating on main ideas.

\section{Bina}

Bina's text production consists of six still images, each image including text and several photos. Three of the images also include recorded voices where (mainly) the text that is written down is read aloud. Overall, this text production gives a collage-like impression.

Image 1 consists of two photos: one of the spaceship that the student found as an illustration in the assignment and one of her friend sitting in a room using her iPad. To the first photo the following sentences are added: 'She can live on the planets.' and 'They can go to all planets.', and to the second, this is added: 'They can drink water from the water tap' (all readable but partly incorrect spelling). The sentences that go with the first photo are also recorded and read aloud, by two voices.

The second image consists of one photo on the left and two photos on the right. On the left you find a photo of a soup pot (from the canteen) and four sentences: 'They can eat soup. They can eat fruit. They can eat meat. They must eat to live on earth.' (readable but partly incorrect spelling). On the right, there is one photo of the students' classmates standing in a row wearing winter clothes, and one of the place in the canteen where you find water and ketchup. The text aside the photo of the classmates is 'They need clothes To Be warm during winter.'

In the next image, number three, there are five photos and one sentence is added to each photo. On the left, there are two photos taken in the schoolyard: one with one of the students' friends in the background and another with a friend in the foreground. On the right, there are another three photos of the schoolyard: one of her friend, one of a swing and one of two classmates using their iPads outdoors. To the photos on the left, the following text is added: 'You can play football. You can go to shop.' (but 'shop' is hard to read because of the spelling). On the right, you find this information: 'u can take a shower' and 'You can play outdoors'. However, the fourth image consists of two photos: one of herself sitting with her iPad (probably taken by a classmate) and one of some bookshelves at school. Beside the first photo, you can read 'You can paint', and beside the next is written 'You can read at library' (but the last word is difficult to read because of the spelling).

\footnotetext{
25 The teacher in this specific class is likely to be inspired by whole language theories (Clay 1991), and (aware of it or not) uses top-down strategies rather than a bottom-up approach, for literacy development.
} 
The next image, number five, consists of four photos taken at school: on the left there are two photos showing where you hang your clothes in the corridor (photo 1 ) and where you get food in the canteen (photo 2). To these photos, the following text is added: 'You can hang clothes' (incorrect spelling) and 'You can eat'. The student's own recorded voice is added here, saying the same things as are written. On the other hand, there are two photos to the right: one of a sign saying 'Woodwork' and one of the school from the outside. To the first photo Bina has added two sentences: 'You can Jöback' (probably 'jobba' in Swedish - 'work' in English) and 'It is good to work'. The added voice relates to this information, saying 'You can work' and 'It is good to work at school'. Beside the second photo Bina has written 'Here is the school', and this is also what the voice tells us. However, in Image 6there are two photos, both of a classmate. In the first photo, she looks down at an iPad and in the second she has her head raised, sitting in the same place. The text beside the first photo says 'You have to go to school to learn' while the text added to the second one is 'You can learn' (but half of the word learn is omitted here). Also, a voice is added to this image, saying, 'One must work at school'.

Even though Bina uses multiple resources, her text production introduces difficulties in making use of the resources to communicate. Her multimodal repertoire could be said to be limited; even though she uses photos that might be relevant to the recipient, a 'reader' may find it hard to relate them to each other and see the point of combining them. When being interviewed, this student also finds it difficult to comment on her text. Instead she relates to a project about Saturn that they had been working on earlier at school.
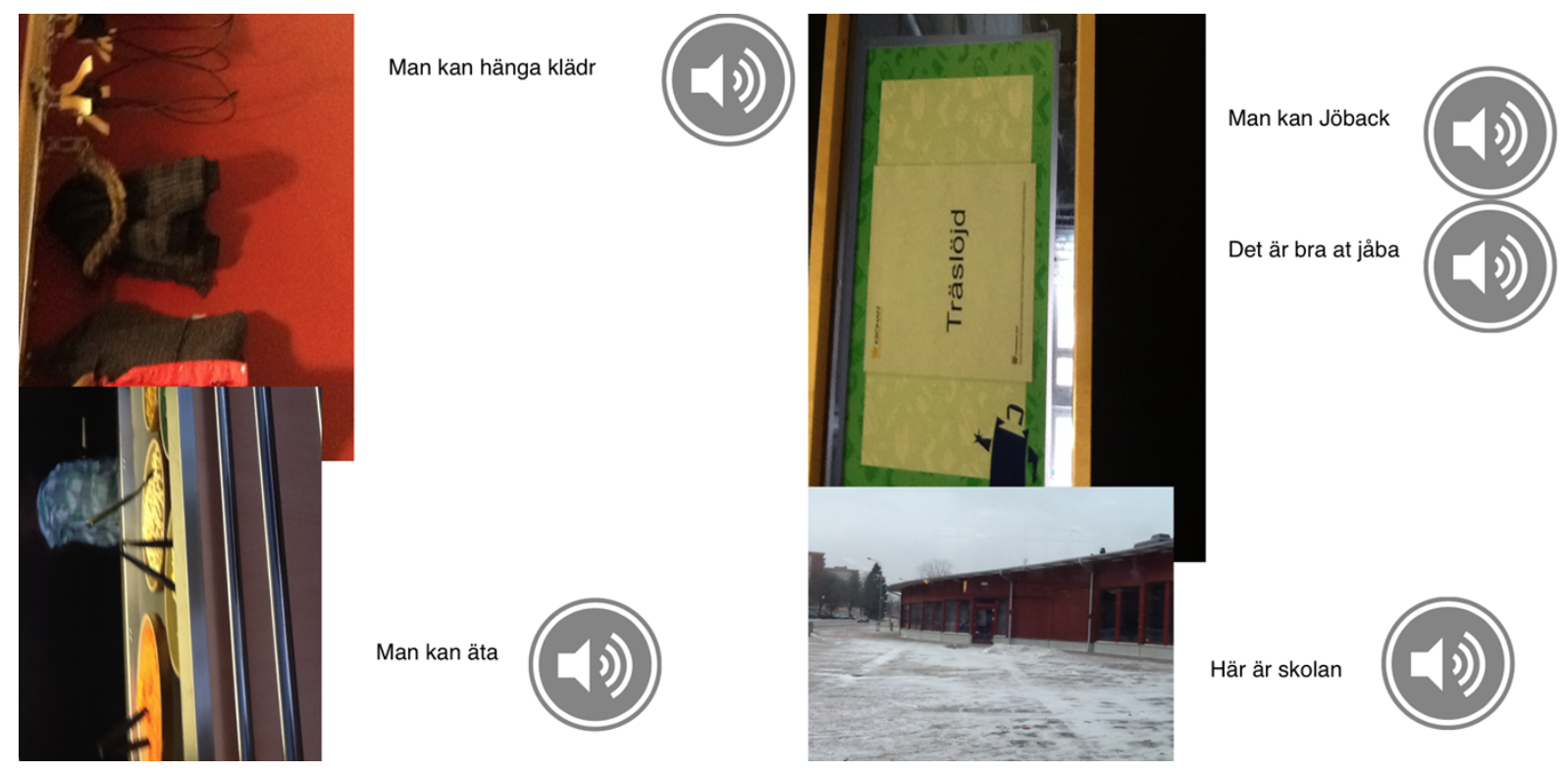

Bina's Image 5.

In the context, it should be pointed out that children are supposed to have natural synesthetic capacities (Cope \& Kalantzis 2010); they are expected to naturally find it easy to use a variety of modes to express themselves - capacities that school literacy are said to separate, instead of building upon. However, Bina's text production shows that synaesthesia in terms of multimodality is a complex process in terms of meaning making. This student does not seem to find the process easy, when it comes to shifting between modes and efficiently making use of the combination of them. Nevertheless, it is obvious that she is more comfortable with one mode than another, and that the starting-point for meaning making that she foregrounds, still images, could be a way of extending this student's repertoire, by trying to get her to shift from this favoured mode to less comfortable ones. Here, the conception of multivocal space could be used to understand what matters to Bina (her friend and the fact that you are supposed to work at school, etc.), and with this as a starting-point develop her story by trying to make sure that the parts constituting it make sense to the reader. Also, Bina's text raises the question of whether it is possible to create a narrative that could be regarded to be a multivocal space 
without voices connected to each other; the text could be argued to be more characterized by heteroglossia than a space with voices related to each other. To find traces of bottom-up or top-down processes in Bina's text is also difficult. However, to strengthen Bina's efforts in taking responsibility for her literacy development, a start might be a talk with her about what matters to her in her narrative.

\section{Ramona}

Ramona's text production consists of eight still images where text and photos are equally important. In Image 1, there is a photo of three spaceships (taken from the written assignment). The background is pink and the text is written in light blue, saying three things in different places in the image: 'Here I have a picture of the alien.', 'Alien' and 'Ramona tells.' All through the text production, Ramona pays attention to the layout of her still images; this is used to indicate similarity and difference, and makes it possible for her to step aside and consider the information needed in the communication.

On the left side of Image 2 is a light blue text on a dark pink background (there is no photo). Here she starts by standing back, saying 'Imagine if an alien arrived on earth and knows nothing. What would we do then? We would tell it what to survive it needs water and air water is needed to drink and air is needed to breathe. What else would we say? We would tall (tell) that it needs his or her mum and dad.' Considering the information needed, she puts a photo of a dark pink mug with water in it (taken from above), standing on a white table. Below it she adds a reflection of her own: 'But imagine if the alien does not know what water is. Hm... What would we do then? I know I have taken a photo of a pink glass with water in it.' (three spelling mistakes and problems with word order). Now the text is written in purple.

In Image 3, Ramona alternates between generalization about what the alien needs (food) and her own particular comments on this. To the left there is a photo taken in the canteen showing food to be served. Here the text is black on a red background, saying: 'Here I have some nice food for the alien.' (incorrect spelling of food, but readable), and further down: 'Mm.... What nice food'. On the right, red text is written on a black background, saying: 'What else does the alien need apart fromwater, air and its mum and dad?', and at the bottom of the image: 'Yes it needs food to eat to survive.'

In Image 4, the colours have changed again. On the left, there is no photo but a text in yellow on a blue background, declaring: 'I would tell the alien that when you wake up you go to the loo (taa, probably toa in Swedish) and wash your teeth. Further down, she comments on this: What else can you tall (tell) the alien?, and even further down she develops her thoughts: You can tall (tell) the alien how to drink milk and how you eat. Again, she shifts between generalization and her own, particular comments, by letting the following information turn up at the bottom of this image: 'Also it is good if you explain ('förklarar' spelled 'feklarar') how you do things, like (typ in Swedish) you tell how you draw a nice flower or a heart.' On the right here, she shows a photo on the top, with a flower and a heart, both hand-drawn on a sheet of paper. Beneath it there is information on what has been presented, as well as her own comments (all in blue text on a yellow background): 'Here I have drawn a flower and a heart.' and (further down) 'Isn't it nice.'

In Image 5, there are no photos on the left, but instead text in purple on a light blue background presenting Ramona's own reflections: 'I will tell a bit more about the alien. The alien needs to go to school to learn maths.' Further down she develops her thoughts: 'It also must learn to write and paint.' At the bottom of this part of the image she adds a photo conveying information on where the alien could develop its abilities: 'Here is my school.)'. To this information a photo is added (on the right side of the image), showing the school entrance with letters saying 'Welcome' and a sign telling people where to find things at school.

In Image 6, Ramona thinks aloud. By using text in turquoise on a grey background, she says 'Hmm..... What else can you write about an alien? I know we can show the alien what to do during the breaks. Hmmm......' Further down she develops her thoughts by addressing the alien personally: 'I know we can show how you play basketball.' She removes the distance to the alien, for herself and for the reader, by using 'we': 'We can also let the alien have a swing.' In this left part of the image, Ramona also delivers information that is good to know, including her own comments on what she is presenting: 'Here I have two pictures of the basketball court and a swing. Then the alien might understand what basketball is and 
swing' (an omitted a here). To the right there are two photos making the information more precise, showing the place in the schoolyard where you can play basketball, and a photo of the swing.

The next image, number seven, consists of text on the left (purple text on black) with another reflection: 'We can also tell the alien about library, yes then the alien learns how to read.' Beneath it Ramona comments on what she has just said: 'Books are good to learn, aren't they?'. Further down she addresses the alien, as well as any possible reader: 'Have a look here. I have cool pictures of library and books.' As a complement to this, two photos are added (on the right), that inform the reader about where to find books: one of the entrance to the school library, including the sign 'Library', and one of shelves filled with picture books.

In the last image, number 8 , the left part is filled with black text on a green background saying 'We can also tell the alien about the alphabet then he will learn letters. That (omitted ' $t$ ') is a good thing later when the alien is going to write then he knows the letters.' Here Ramona continues presenting her thoughts from Image 7, by connecting to the contents of the books. She also develops her thoughts further, by (again) commenting on her own ideas: 'How cool, he will know very many things.' ('very' with slightly incorrect spelling - 'jete' in Swedish, meaning 'jätte'). Using her imagination, she adds: 'It will also be fun to know what the alien is going to write, wouldn't it?' To make it clear to the reader what it is all about, there are two photos (on the right) of the alphabet on the wall of the classroom, showing different parts of it. To the first photo Ramona has added a recording of sound from the classroom (five seconds of small talk), which could be regarded as a kind of information on what school work is all about. This recording, as an ending, could also be said to conceptualize what Ramona stresses throughout the whole story: that it is important to learn new things if you are an alien arriving on earth, and that this could be done at school.

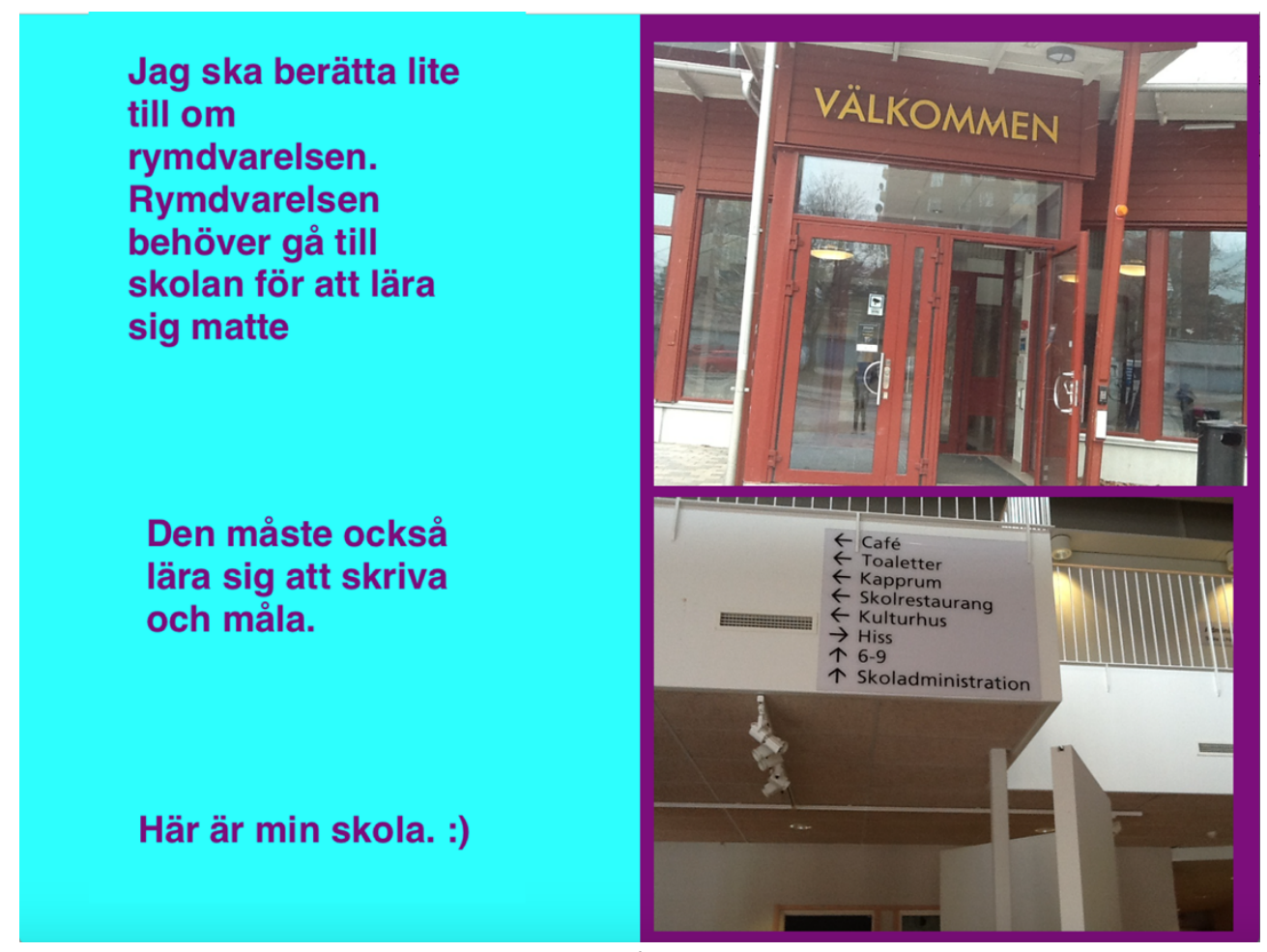

Ramona's Image 5.

As a multimodal text producer, Ramona is an active conceptualizer, who is able to generalize from the particular. When being interviewed, she comments on her working process by saying 'first I thought, and then I started to make my text.' She is also thinking aloud throughout the whole working process. A typical example of this is her comment 'What should we do if the alien does not know...?'. In fact, you could say that Ramona's text production makes it clear what constitutes a new situation when digital 
media are being used. Here we find learning that engages the learner as co-constructor of concepts, as a definer and theory-maker, since Ramona reflects on what she stresses as important to know for the recipient of her text production. She draws distinctions by the use of contrasting colours when writing. Also, she accentuates certain themes in her 'text' by her use of colours. Pink, purple and blue colours for instance, are used in Image 1 and 2 when she focuses on the importance of drinking, while in Image 3 when Ramona deals with a new perspective on what is needed - she uses a new colour theme: black and red. In the rest of her text production she gradually goes back to the blue scale colours, while step by step summing up what is being offered at school if you want to learn new things. By this, her use of colours, she differs from the other students, and even if Ramona is not fully aware of why she creates her text production as she does, this could probably be explained by her ability to stand back and consider the information needed in the communicative situation. In fact, the ability Ramona has to think about her thinking (metacognition) requires weaving together the experiential and the conceptual, and it is this weaving that could be said to constitute her multivocal space. Thus, it is the quality of voices that are not only linked to each other but also interact (as in a choir), that makes this text production work as a presentation that could be perceived as complete to an intended recipient.

Since Ramona, while being asked about her working process, stresses that she started thinking before she made her text, her thinking is likely to be closer to a top-down process than a bottom-up process. However, she is not consistent - now and then she leaves the path of main ideas and seems to start from 'the bottom' to explore what her text is all about, by beginning with details to see what she will end up with. Perhaps it is the fact that she is happy to combine her 'written' story with narratives constituting her identity as a schoolgirl that makes it easier for her to create the text production, and not only her linguistic and digital abilities; by her text production she seems to take full responsibility for her own literacy development.

\section{Students' multivocal spaces and development of literacy}

To sum up, the concept of multivocal spaces could be used to capture how texts are being created and constituted by 'voices' emanating from experiences acquired inside and outside school. The voices dominating the students' texts could be said to constitute narratives not only emanating from the students' experiences socially and historically, but also conceptions about what they would like to become as writers (cf. Bruner 2002). Accordingly, Ramona is likely to be a text producer that connects her story to other successful stories at school, which altogether makes the narrative of her as a successful student even more developed than before, both in her own eyes and in the eyes of others. Also, Edy could be said to try hard to develop a narrative of his own as someone who is struggling hard at school. What kind of narratives of themselves Zaid and Bina are contributing to - and wish to create is more unclear; Zaid could be regarded as a young student who does not care about norms of how text productions are usually constituted, and the same could be said about Bina. Here the teacher, as a representative of the majority language, has the power to influence the narratives that constitute the students; in fact, the narratives that students like Zaid and Bina develop about themselves at school are dependent on the teacher. Thus, by focusing on multivocal spaces as narratives, which in turn are constituted by more or less dominating voices, not only the creation of the texts could be studied but also how the creation of texts is likely to be due to negotiations within and outside the students' minds. As Tierney writes (2018), spaces allowed for in educational systems are politically embedded; some spaces may operate and support meaning making that is seamless, while other spaces may prove inaccessible or present barriers to meaning making and impede peoples' ability to be protagonists. By the text productions presented, viewed as manifestations of literacy being processed, the students' subordination becomes obvious; the students are fully dependent on the views of meaning making surrounding them, which may involve varying degrees of respect for cultural ways of presenting their knowledge as their journey across borders. However, the (political) contexts in which multivocal spaces take place (locally), is not the main focus of the study presented here.

As a tool for the analysis, sociosemiotics has been useful (Kress \& van Leeuwen 2006); all text productions are constituted by signs expressed by modes, as demonstrated above. However, to convert from one mode to another in a communicatively meaningful way, and make a point of combining 
different modes, seems to be difficult. At the same time, the variety of text productions gives some useful information: by the use of modes the students reveal their preferences of modes. Of course, these preferences are context related and change over time. However, in all contexts it must be regarded as useful from a language developing perspective to pay attention to these preferences and from these develop the abilities to communicate that the students need. Respect for cross-cultural meaning making, locally, is then a prerequisite.

As shown above, all students work hard to communicate, and by their text productions it is possible to discern their working processes (top-down, bottom-up, etc.). In this context, the possibility that agency offers to the students is crucial, by an assignment encouraging the use of digital resources; agency could here be said to be a prerequisite for conceptualization and the creation of multivocal spaces that allow the students to communicate.

\section{References}

Bailey, B. (2007). Heteroglossia and boundaries. In M. Heller (Ed.), Bilingualism. A Social Approach (pp. 257-276).

Basingstoke, UK: Palgrave.

Bakhtin, M. (1981). The Dialogic Imagination: Four Essays. Austin and London: University of Texas Press.

Bakhtin, M. (1994). Problems of Dostoevsky's poetics. In P. Morris (Ed.), The Bakhtin Reader. Selected Writings of Bakhtin, Medvedev, Voloshinov (pp. 110-113). London: Arnold.

Barton, D. (2007). Literacy. An Introduction to the Ecology or Written Language. MA: Blackwell.

Bearne, E. (2009). Multimodality, literacy and texts: Developing a discourse. Journal of Early Childhood Literacy, 9 (2), 156-187.

Blommaert, J. (2010). The Sociolinguistics of Globalization. Cambridge: Cambridge University Press.

Bruner, J. (2002). Kulturens väv. Utbildning i kulturpsykologisk belysning. Göteborg: Daidalos.

Clay, M. (1991). Becoming literate. The Construction of Inner Control. Portsmouth: Heinemann.

Cope, B. \& Kalantzis, M. (2010). Multiliteracies in Motion. New York and London: Routledge.

Creese, A. (2008). Linguistic Ethnography. In Encyclopedia of Language and Education (pp. 3424-3436). New York: Springer.

Dewilde, J. (2016). Det er bare i hjertet mitt»: Portrett av en transspråklig ungdom som diktskriver. SkandinaviskeSprogstudier, 7 (2), 46-62.

Garcia, O. (2009). Bilingual Education in the 21'st Century. A Global Perspective. Chichester: Wiley-Blackwell.

Garcia, O. \& Wei, L. (2014). Translanguaging. London: Palgrave.

Heath, S. B. (1983). Ways with Words: Language, Life, and Work in Communities and Classrooms. Cambridge: Cambridge University Press.

Jewitt, C. (2008). Multimodality and Literacy in School Classrooms. Review of Research in Education, 32 (1), 241267.

Kim, G. M. (2016). Transcultural digital literacies: Cross-border connections and self-representations in an online forum. Reading Research Quarterly, 51, 199-219.

Kress, G. \& van Leeuwen, T. (2006). Reading Images. The Grammar of Visual Design. London: Routledge.

Lyngfelt, A. (2018). Reading in your first and second language. On the use of prior knowledge when processing fictional texts at school. Social Sciences and Education Research Review, 4 (2), 78-99.

Sofkova Hashemi, S. \& Cederlund, K. (2017). Making room for the transformation of literacy instruction in the digital classroom. Journal of Early Childhood Literacy, 17 (2), 221-253.

Street, B. (1984). Literacy in Theory and Practice. Cambridge: Cambridge University Press.

Swain, M. (1985). Communicative competence: Some roles of comprehensible input and comprehensible output in its development. In S. Gass, \& C. Madden (Eds.), Input in second language acquisition (pp. 235-253). Rowley, MA: Newbury House.

Tierney, R. J. (2018). Toward a Model of Global Meaning Making. In M. Sailors (Ed.), Journal of Literacy Research (pp. 1-26). New York, NY.

Vasquez, V. M. \& Felderman, C. B. (2013). Technology and Critical Literacy in Early Childhood. New York: Routledge. Wei, L. (2011). Moment Analysis and Translanguaging Space: Discursive Construction of Identities by Multilingual Chinese Youth in Britain. Journal of Pragmatics, 43 (5), 1222-1235. 